\title{
Integrated clinical and quality improvement coaching in Son La Province, Vietnam: a model of building public sector capacity for sustainable HIV care delivery
}

\author{
Lisa A. Cosimi ${ }^{1,2^{*}}$, Huong V. Dam ${ }^{3}$, Thai Q. Nguyen ${ }^{4}$, Huyen T. Ho ${ }^{3}$, Phuong T. Do ${ }^{4}$, Duat N. Duc ${ }^{4}$,
} Huong T. Nguyen ${ }^{4}$, Bridget Gardner ${ }^{2}$, Howard Libman ${ }^{2}$, Todd Pollack ${ }^{4}$ and Lisa R. Hirschhorn ${ }^{1,5,6}$

\begin{abstract}
Background: The global scale-up of antiretroviral therapy included extensive training and onsite support to build the capacity of HIV health care workers. However, traditional efforts aimed at strengthening knowledge and skills often are not successful at improving gaps in the key health systems required for sustaining high quality care.

Methods: We trained and mentored existing staff of the Son La provincial health department and provincial HIV clinic to work as a provincial coaching team (PCT) to provide integrated coaching in clinical HIV skills and quality improvement (QI) to the HIV clinics in the province. Nine core indicators were measured through chart extraction by clinic and provincial staff at baseline and at 6 month intervals thereafter. Coaching from the team to each of the clinics, in both QI and clinical skills, was guided by results of performance measurements, gap analyses, and resulting QI plans.

Results: After 18 months, the PCT had successfully spread Ql activities, and was independently providing regular coaching to the provincial general hospital clinic and six of the eight district clinics in the province. The frequency and type of coaching was determined by performance measurement results. Clinics completed a mean of five QI projects. Quality of HIV care was improved throughout all clinics with significant increases in seven of the indicators. Overall both the PCT activities and clinic performance were sustained after integration of the model into the Vietnam National QI Program.

Conclusions: We successfully built capacity of a team of public sector health care workers to provide integrated coaching in both clinical skills and QI across a province. The PCT is a feasible and effective model to spread and sustain quality activities and improve HIV care services in a decentralized rural setting.
\end{abstract}

Keywords: Quality improvement, Coaching, Teamwork, Resource limited

\section{Background}

Scale-up of HIV care and treatment has resulted in an estimated 9.7 million people on treatment in lower- and middle-income countries [1]. Training and on-site clinical mentoring have been important components of many national scale-up efforts [2-6]. However, it is

\footnotetext{
* Correspondence: Icosimi@partners.org

'Brigham and Women's Hospital, 75 Francis St, Boston, MA 02115, USA

${ }^{2}$ The Partnership for Health Advancement in Vietnam, Beth Israel Deaconess Medical Center, 1309 Beacon St, Brookline, MA, USA

Full list of author information is available at the end of the article
}

increasingly recognized that strengthening healthcare systems in addition to clinical knowledge is necessary to ensure quality of care delivery, long-term sustainability and universal access to effective treatment $[7,8]$.

Addressing health system gaps at the clinic and local level are beyond the scope of traditional HIV training, clinical coaching, and other continuing medical education approaches that focus on health care worker (HCW) knowledge and skills. Published reports on training and clinical coaching have generally shown limited impact on quality of care, with modest, short-term

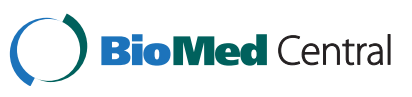


improvements seen in single performance measures such as prescribing practices, tuberculosis and sexually transmitted infection screening [9-14].

Increasingly, work to improve quality of HIV care in resource-limited settings has aimed to build capacity for systems-focused improvement $[4,7,15,16]$. However, implementation of many quality improvement (QI) programs has been hindered by factors including human resource shortages and turnover, lack of knowledge and leadership in QI, lack of material resources, and competing health care delivery priorities $[17,18]$. While there have been examples of effective scale-up of QI-focused programs in public sectors, published reports of broader sustained improvements in quality of care in low- and middle-income settings remain limited $[16,19-21]$. Additional models that systematically strengthen the quality of healthcare delivery are needed.

Vietnam is a lower middle-income country with a population of approximately 90 million and an estimated HIV prevalence of $0.4 \%$ [22]. By the end of 2013, 80,000 persons were receiving treatment through a network of hospital and community-based clinics located throughout the country's 63 provinces [23]. As in many countries, the initial delivery and scale-up of treatment services was supported by intensive efforts, including didactic training and onsite coaching, to build the clinical skills of HCWs working in the HIV clinics. However, this initial support was not designed to increase HCW and facility capacity to diagnose and improve systems-level gaps that threaten quality. We describe the initial results of a collaboration with provincial health officials in the remote province of Son La, Vietnam designed to build capacity of a team of provincial HCWs and public health staff to provide coaching in clinical skills and in QI. The purpose of the study was to understand whether a provincial coaching team (PCT) model built within the existing infrastructure of the public healthcare system could improve the quality of HIV care throughout the province.

\section{Methods}

\section{Setting}

Son La is a large mountainous province located in North Vietnam along the Lao border. It has a population of $1,092,700$ and a per capita income approximately half the national average [24]. The province has one of the highest HIV prevalence rates in the country $(0.6 \%)$ [23]. HIV care is delivered through nine HIV outpatient clinics. The largest clinic, opened in 2009, is located at Son La Provincial Hospital (Provincial clinic), and in 2013 provided care to 700 patients. Training of HIV providers in this clinic started with an in-service didactic training in 2009 focused on the care and treatment of HIV-infected patients, followed by quarterly clinical mentoring by HIV clinical experts. The eight remaining clinics are located in smaller district-level health care facilities, the furthest of which is a 4-h drive from the provincial capital. Staff working in these clinics also attended an in-service didactic HIV training and received periodic clinical skills coaching from the Provincial clinic physicians. Son La government health staff from the Provincial People's AIDS Committee (PAC) were responsible for managing and ensuring the quality of all HIV programs in the province and supported the sites through regular audits and supervisory visits. However prior to 2011, clinical coaching occurred separately from audit and supervision, and routine performance measurement and structured QI activities were not occurring.

\section{Intervention}

Beginning in April 2011 our organization, The Partnership for Health Advancement in Vietnam (HAIVN), partnered with the Son La PAC to train members of the PCT to integrate QI coaching into their existing clinical mentoring, auditing, and supervision responsibilities. The PCT included a physician from the Provincial hospital clinic to provide HIV clinical and QI coaching to the district-level clinics, and staff members from the PAC to provide QI coaching, as well as to plan and implement the provincial-wide QI program (Fig. 1). Staff from the PAC and all staff working in the Son La Provincial clinic (including the physician identified to be the clinician member of the PCT) were trained in QI methodology through a two-day skills-building workshop. The workshop covered principles of quality and QI, indicator development, routine performance measurement, data collection and utilization, and QI project planning and implementation. Following the initial training, attendees gained hands-on experience supported by coaching from HAIVN staff to complete a baseline measurement of HIV quality in the provincial clinic.

\section{Study design}

We conducted a prospective evaluation of the quality of care in seven HIV clinics before and after implementation of the coaching activities by the PCT.

\section{Performance measurement and population}

To measure quality of care, core indicators were developed from existing international standards and national QI programs $[25,26]$. Indicators included documentation of TB screening, adherence screening, whether eligible patients received cotrimoxazole (CTX) prophylaxis, CD4 cell count testing done in the past 6 months, routine lab monitoring (hemoglobin ( $\mathrm{Hgb}$ ), alanine aminotransferase $(\mathrm{ALT}))$ in the previous 6 months, antiretroviral therapy (ART) start within 30 days of determination of clinical 


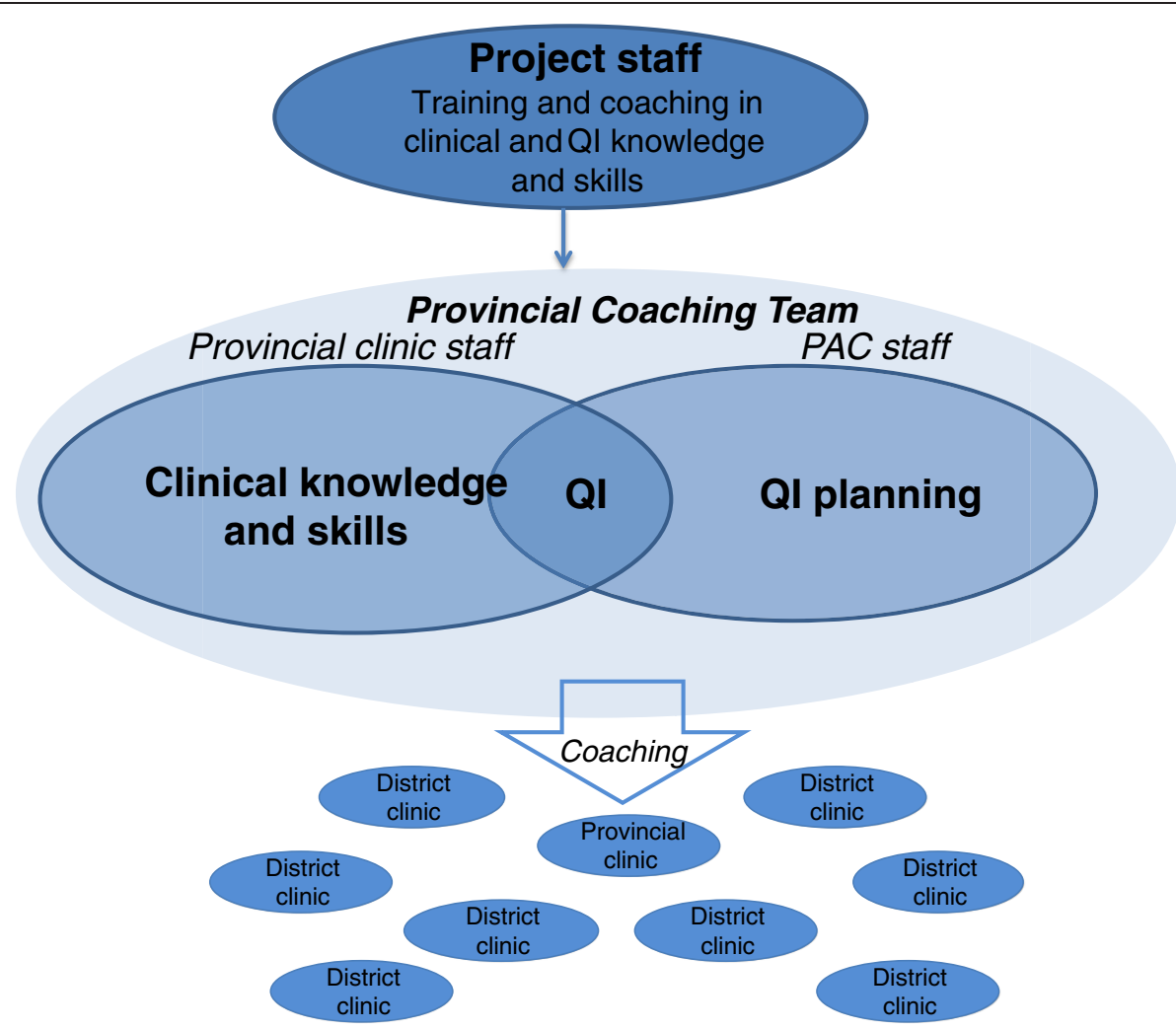

Fig. 1 Model of Provincial-wide Capacity Building: Staff from the provincial clinic and staff from the Son La People's AIDS Committee were trained in QI methodology and mentored to develop practical skills through implementation of QI at the Son La clinic by HAIVN staff. The provincial coaching team then provided coordinated clinical coaching and QI coaching to the district HIV clinics located throughout the province

eligibility, and visit adherence. The visit adherence indicator changed after the first measurement at the clinic in Son La Provincial Hospital ("any missed visits in the previous year") to "any missed visits in the previous 6 months" in all subsequent measurements done with HAIVN support through February 2013. Documentation of hepatitis $\mathrm{C}$ virus $(\mathrm{HCV})$ screening was added as an indicator after the first measurement at the Son La Provincial Hospital clinic.

Data were extracted by chart review of a systematic sampling of patients who were active in care, defined as one or more visits in the previous 3 months for patients on ART or 6 months for patients not on ART. The sample size in each facility was calculated to be able to measure performance rates at the clinic level with a $95 \%$ confidence interval $+/-10 \%$ for indicators with a $50 \%$ rate. Data were extracted from charts every 6 months by clinic staff with coaching and oversight from PAC staff.

\section{Quality improvement}

Following the initial quality measurement, HAIVN staff coached the PCT and provincial clinic staff to review and interpret the results, prioritize which gaps to improve, determine root causes, and develop and implement QI projects. This coaching was done through both on-site visits and by telephone. Coaching was initially provided every 1 to 2 months decreasing to quarterly after the first 6 months. Targeted clinical coaching was also provided by HAIVN staff to the Son La PCT and focused on improving clinical skills gaps identified in the performance measurement.

Once the PCT had gained skills in measurement, QI implementation, and clinical and QI coaching, HAIVN supported them to train district clinic staff in QI and provide follow-up clinical and QI coaching. In July 2011, the PCT began to train and coach the first three district clinics on performance measurement and QI. Three months later, three additional clinics were added. During quarterly provincial visits and regular phone conversations, HAIVN supported the members of the PCT by reviewing results, progress, and barriers in QI implementation and providing coaching on how to address identified challenges. This support was designed to further build the PCT's capacity to strengthen QI efforts throughout the province (Fig. 1).

Three of the district clinics and the Provincial clinic completed a baseline, 6-month, and 12-month performance 
measurement. Three additional clinics had reached 6 months of follow up by the end of 2012. QI support in the remaining two district clinics was implemented in 2013, occurring just as the entire provincial QI program was selected to transition to the expanding national QI effort.

\section{Integration into Vietnam National QI Program}

In early 2013, the VAAC began to roll out a national QI program for HIV care and treatment clinics. The HAIVN-supported provincial QI efforts transitioned over to the national QI program in February 2013. At this time, staff of the Son La provincial clinic and the six district clinics repeated a quality measurement using the national performance indicators. The only indicator definition that changed from the provincial measures already in use was visit adherence (from presenting as scheduled for all visits in the previous 6 months to only requiring presentation at the most recent scheduled visit). The national indicators also did not include routine $\mathrm{Hgb}$, liver function tests or $\mathrm{HCV}$ testing.

After this performance measurement, staff from the clinics attended a national QI training. This training served as the initial introduction to QI for staff that joined the clinic after 2012 and refresher for previously trained staff. Following this training, the existing Son La PCT continued to support all clinics on a quarterly basis to review performance gaps, provide relevant QI and clinical skills coaching, and to develop and implement QI projects and plans. HAIVN staff remained available for telephone support to the PCT and accompanied the national technical working group on one visit to the province after the training.

\section{Analysis}

We did a pre-post analysis of the change in performance measurement at the Provincial clinic and the first six district clinics before and after implementation of the PCT model and following transition to the national program. Performance rates were compared between the baseline, 6 and 12-month measurement using a chisquared test. $P$ value of $<0.05$ was considered statistically significant. Visit adherence is only reported for the initial phase (pre-transition) because of the change to the national indicator. Data analysis was performed using STATA software version 12 .

\section{Ethical considerations}

The work was exempted from Institutional review as a quality improvement activity by both the U.S. Centers for Disease Control and Prevention and the Beth Israel Deaconess Medical Center IRB and was approved by the Vietnam Administration for AIDS Control. To ensure patient confidentiality, no patient identifiers were extracted during chart review and only unique study codes were entered into the database.

\section{Results \\ Performance Measurement and QI at Son La Provincial Hospital Clinic \\ Baseline quality of care}

Despite a well-trained and experienced HIV clinic team, the baseline measurement identified several quality gaps at the provincial clinic (Fig. 2). The majority ( $83 \%$ ) of patients had documented medication adherence screening, over $90 \%$ of patients had appropriate ALT and Hgb monitoring, and $80 \%$ of patients had CD4 testing in the previous 6 months. However, only $15 \%$ of patients were screened for symptoms of TB, $31 \%$ of eligible patients received cotrimoxazole, and $52 \%$ of patients in the previous 6 months started ART within 30 days of clinical eligibility. Fewer than half (45\%) of patients had come on time to their visits in the previous year.

\section{QI}

The Provincial clinic staff identified several possible root causes for the gaps, including poor chart documentation, and designed QI projects after the first measurement to improve three prioritized areas: TB screening, missed visits, and chart documentation. To improve TB screening, the clinic made use of a checklist of the four screening symptoms from the national guidelines (cough, fever, weight loss, night sweats) that was stamped into the chart by the nurse at the beginning of each clinic visit and served as a prompt for the examining physician. At the same time the data supporting the use of screening symptoms in active $\mathrm{TB}$ case finding were presented by HAIVN project staff in a brief lecture. These interventions led to rapid improvement in TB screening, which was maintained in future measurements. To decrease the number of missed visits, the clinic staff focused on improving their outreach to patients when they came late or missed their appointments. Through frequent checks of a small number of charts from patients seen in the previous week, the clinic staff was able to monitor whether their plans were having an impact and make adjustments where needed.

After the second performance measurement at 6 months, there was an upward trend in performance across all indicators. TB screening increased to $91 \%$ of charts, cotrimoxazole prophylaxis was documented in $82 \%$ of eligible patients, and CD4 testing was documented in $84 \%$ of patients. By 12 months, TB screening, routine lab monitoring, and HCV screening reached $100 \%$, and statistically significant improvement was seen in all of the remaining indicators whose definitions remained constant (Fig. 2). 


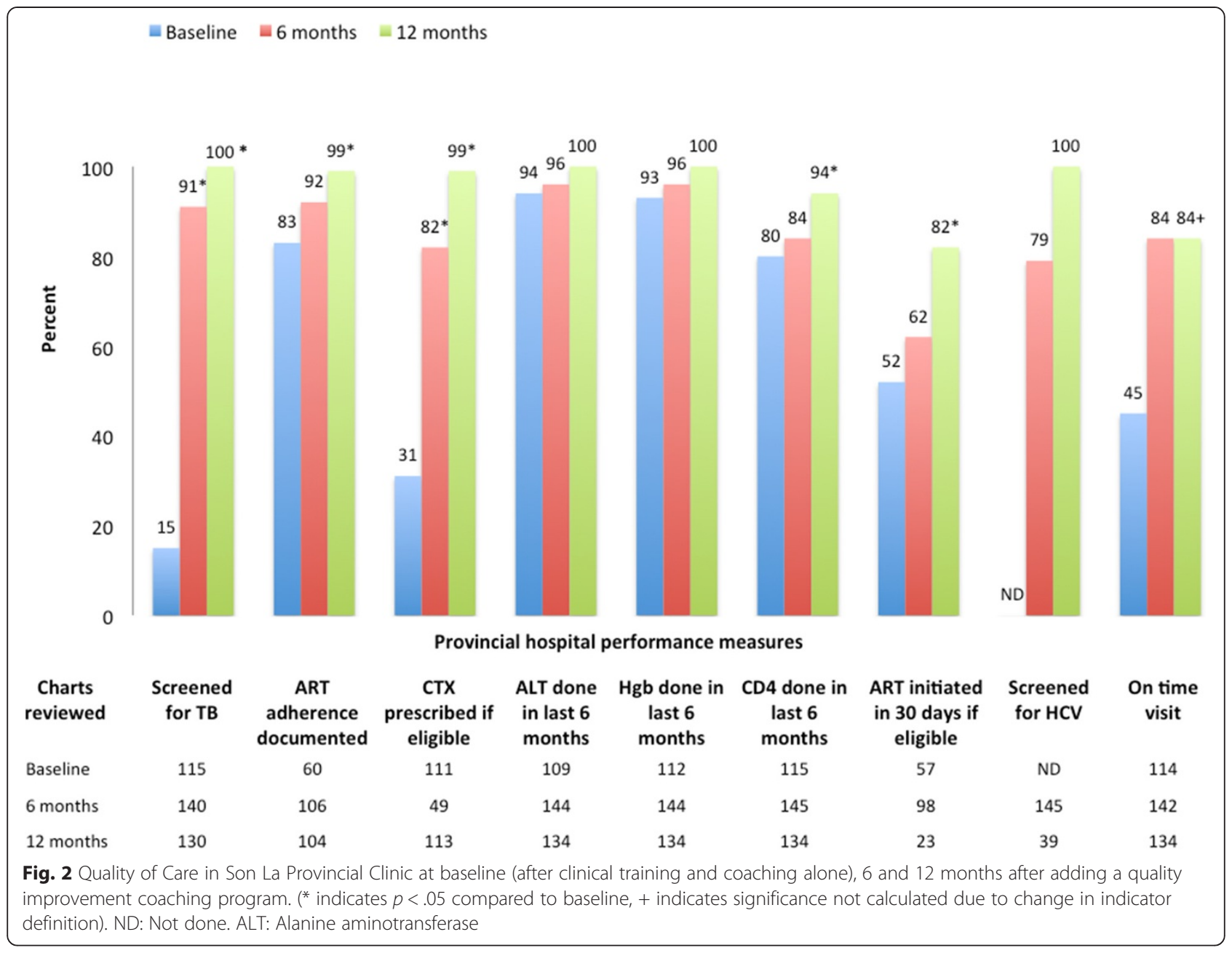

\section{Spread of QI to district clinics by the Provincial Coaching Team}

Across district clinics, the baseline performance measurement revealed gaps in TB screening (18\%), cotrimoxazole prophylaxis $(75 \%)$, and ART initiation within 30 days (62\%). Documentation of adherence screening was found in $54 \%$, and lab monitoring and CD4 testing in the last 6 months was found in 65 and $72 \%$ of patients, respectively (Fig. 3). QI training and baseline measurements at the district clinics were followed by quarterly on-site visits to the clinics and periodic phone calls by the PCT to assist clinic staff as they implemented their interventions. Clinical coaching was provided by the Son La clinic HIV physician to the district clinic staff and tailored based on gaps in clinical practice identified from the measurement results. By December 2012, these six district clinics were actively implementing QI interventions and completed an average of five QI projects with the most frequent areas including improving lab testing, TB screening, and decreasing missed or late visits (Table 1 ).
By the 6-month measurement, the overall quality in the six district clinics had significantly improved $(p<.05)$ in TB screening, adherence counseling, cotrimoxazole prophylaxis, Hgb and ALT monitoring, HCV screening, and on-time visits (Fig. 3). The first three clinics also completed a 12-month measurement prior to roll out of the national program, with further improvement seen in nearly all of the indicators. ART initiation within 30 days reached $91 \%$, and on-time visits in the previous 6 months increased to $83 \%$ from the average baseline of $65 \%$ (in these three clinics). Not everything improved, with CD4 testing in the previous 6 months remaining stable at $74 \%$ and $\mathrm{HCV}$ screening improving only to $40 \%$ in the three clinics completing a 12-month measurement (Fig. 3).

\section{Sustained Quality and QI coaching Following Integration into the National QI Program}

Six months following the integration of the Son La QI efforts into the National Program, the PCT continued to independently support QI activities in the HIV clinics throughout the province. TB screening and adherence 


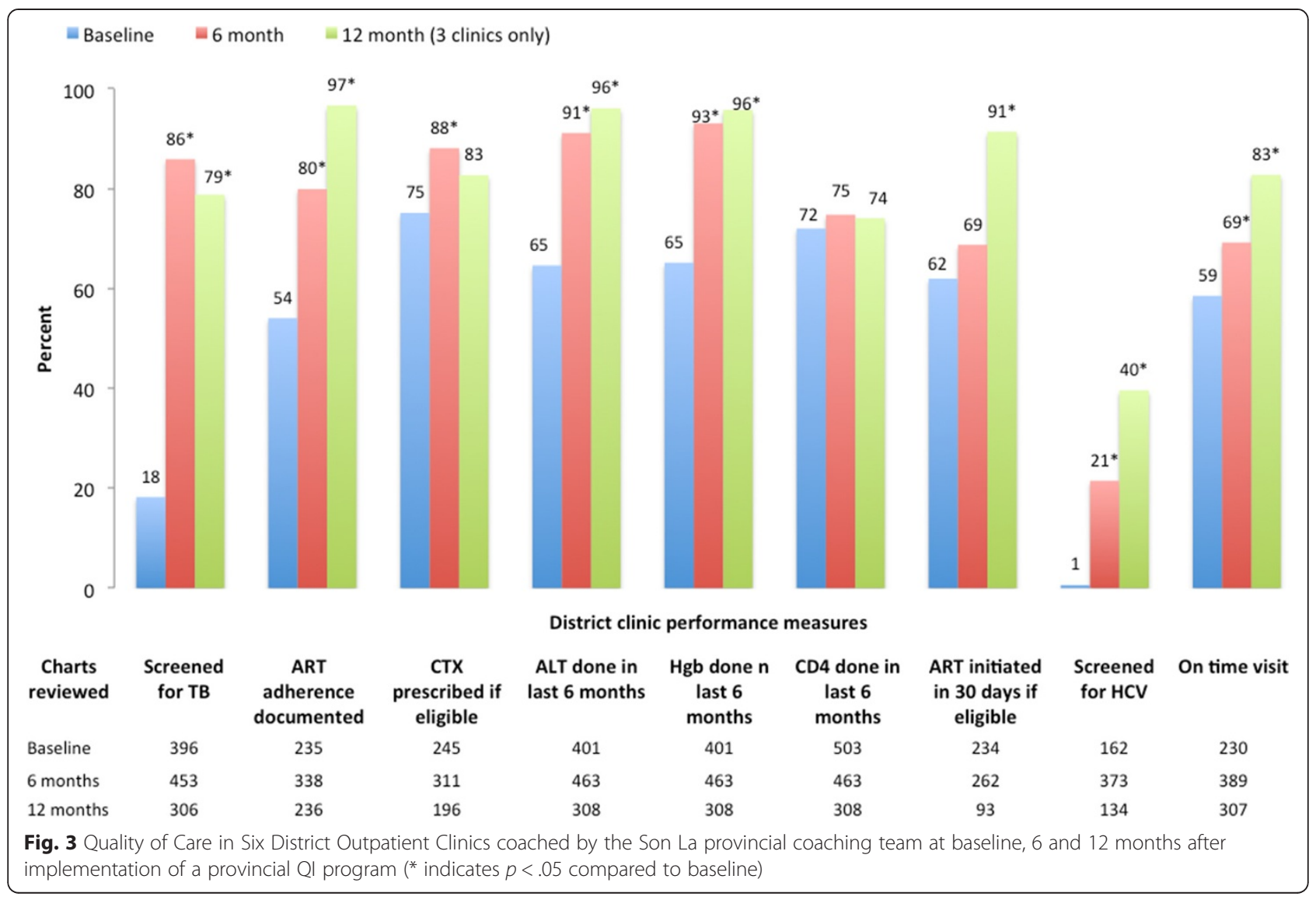

measurement remained high in the provincial clinic and improved in the district clinics (Fig. 4a and b). CD4 testing declined slightly in the final measurement at the provincial clinic (Fig. 4a). In the district clinics, routine CD4 testing (75\%) remained essentially unchanged in all measurements. Cotrimoxazole prophylaxis rates declined in both provincial and district clinics. While the rates were initially maintained in the provincial clinic, they dropped slightly at 12 months (97 to $89 \%, p<.05$ ). Cotrimoxazole prophylaxis dropped at six months (85 to $60 \%, p<.05)$ in the district clinics (Fig. 4b). This decline was attributed to a supply chain gap and performance in the district clinics increased to $82 \%$ in the most recent measurement. ART initiation within 30 days dropped in both the provincial and district clinics although the change at the provincial clinic did not reach statistical significance.

\section{Discussion}

We describe the effectiveness of a model to build capacity of a team of existing public health sector staff to improve the quality of HIV care in a remote mountainous province in Vietnam. The model built critically important leadership and capacity for quality monitoring and QI coaching within in the provincial structure responsible for overseeing HIV care, resulting in a culture for change in the clinics. The approach of building on existing public-sector infrastructure and responsibilities ensured the development of a team able to effectively and rapidly lead the scale-up of QI. The model led to improved quality of HIV care across multiple remotely located district clinics without additional staffing. In addition, the approach of integrating into existing public sector infrastructure allowed the work to successfully transition to the national HIV QI program, with no interruption of the on-site support provided by the PCT, ongoing performance measurement, QI activities, and continued quality in a number of areas.

The model represented a change from the supervision and auditing previously performed by provincial level staff to active data-driven coaching that empowered clinic staff to identify and address gaps. The combined clinical and QI coaching helped improve identified knowledge and skills gaps while building capacity for needed systems and culture change. This approach of linking data feedback with action plans has been identified as critical to making supervision more effective [27]. The approach also allowed the PCT to prioritize efforts to 
Table $1 \mathrm{Ql}$ projects implemented by Son La HIV clinics

\begin{tabular}{|c|c|}
\hline Priority gaps to improve & Description of QI projects implemented \\
\hline \multirow{7}{*}{$\begin{array}{l}\text { Lab testing (ALT, } \\
\text { hemoglobin } \\
\text { and CD4) (6 clinics) }\end{array}$} & $\begin{array}{l}\text { - Place template for monitoring routine } \\
\text { testing in all patient charts }\end{array}$ \\
\hline & $\begin{array}{l}\text { - Review which patients will need lab testing } \\
\text { prior to clinic }\end{array}$ \\
\hline & $\begin{array}{l}\text { - Schedule patients who will require similar } \\
\text { testing on the same day }\end{array}$ \\
\hline & $\begin{array}{l}\text { - Review reasons for routine testing with } \\
\text { patients }\end{array}$ \\
\hline & $\begin{array}{l}\text { - Contact patients who will need lab tests } 1-2 \\
\text { days in advance }\end{array}$ \\
\hline & $\begin{array}{l}\text { - Make specific date for doing CD4 test each } \\
\text { quarter }\end{array}$ \\
\hline & $\begin{array}{l}\text { - Review all patients who need to do CD4 } \\
\text { test }\end{array}$ \\
\hline \multirow[t]{3}{*}{ TB screening (5 clinics) } & $\begin{array}{l}\text { - Use TB stamp or write } 4 \text { TB symptoms } \\
\text { screening questions in chart }\end{array}$ \\
\hline & - Remind staff in weekly meetings. \\
\hline & $\begin{array}{l}\text { - Place reminders on doctor's desk to record } \\
\text { TB screening }\end{array}$ \\
\hline \multirow[t]{5}{*}{ Missed visits (5 clinics) } & $\begin{array}{l}\text { - Logbook created and used to monitor } \\
\text { missed visits }\end{array}$ \\
\hline & $\begin{array}{l}\text { - Follow up missed visits with phone call or } \\
\text { home visit (treatment supporters or nursing } \\
\text { staff) }\end{array}$ \\
\hline & $\begin{array}{l}\text { - Improve counseling on importance of } \\
\text { attending scheduled clinic visits for patients } \\
\text { starting and on ART }\end{array}$ \\
\hline & $\begin{array}{l}\text { - Update patients' contact information at } \\
\text { each visit }\end{array}$ \\
\hline & $\begin{array}{l}\text { - Group patients and schedule on the same } \\
\text { day each month to more easily monitor for } \\
\text { missed visits. }\end{array}$ \\
\hline \multirow{4}{*}{$\begin{array}{l}\text { CTX prophylaxis }(2 \\
\text { clinics) }\end{array}$} & - Review all eligible patients not yet on CTX \\
\hline & $\begin{array}{l}\text { - Update clinic staff on new guideline on CTX } \\
\text { prophylaxis }\end{array}$ \\
\hline & - Make plan for preparing CTX in advance \\
\hline & $\begin{array}{l}\text { - Document in patient charts if patient buys } \\
\text { CTX at outside pharmacy }\end{array}$ \\
\hline \multirow[t]{2}{*}{$\begin{array}{l}\text { ART initiation within } \\
30 \text { days ( } 2 \text { clinics) }\end{array}$} & $\begin{array}{l}\text { - Make a list of eligible patients to contact } \\
\text { and remind them to come to clinic for ART } \\
\text { treatment }\end{array}$ \\
\hline & $\begin{array}{l}\text { - Improve counseling prior to ART eligibility } \\
\text { for patient at each visit }\end{array}$ \\
\hline \multirow[t]{2}{*}{$\begin{array}{l}\text { Patient chart } \\
\text { documentation ( } 4 \\
\text { clinics) }\end{array}$} & $\begin{array}{l}\text { - Review required elements of } \\
\text { chart documentation at staff } \\
\text { meetings }\end{array}$ \\
\hline & $\begin{array}{l}\text { - Improve organization and filing of charts, } \\
\text { and ensure all charts have complete patient } \\
\text { identification } \\
\text { number. }\end{array}$ \\
\hline
\end{tabular}

Table 1 Ql projects implemented by Son La HIV clinics (Continued)

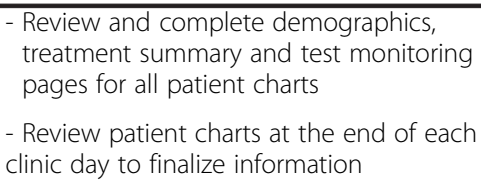

sites with the lowest performance and to tailor activities based on identified gaps. This prioritization is critically important in the setting of limited resources and the travel time required for on-site visits.

Some identified gaps lent themselves to simple local solutions that resulted in rapid improvements. Poor documentation of care provided was a common gap across all of the district clinics, and an initial focus on appropriate documentation contributed to improvement in multiple indicators including adherence assessment and lab testing. The implementation of the TB stamp as a simple tool to improve screening was very successful. This tool was shared by the coaching team and quickly adopted by other HIV clinics, accelerating the improvement process and highlighting the advantage of a provincial-wide approach able to facilitate peer-to-peer learning.

However, gaps from larger systems issues were more challenging to improve and maintain at the clinic level. For example, CD4 testing was performed at only one provincial-level lab and only once per week. If reagents were in short supply, a sample was not sent to the lab, or if a patient did not return for testing on the appropriate day, there were delays in the test being done, resulting in no improvement in the CD4 indicator at the district clinics and a decline in the final provincial clinic measurement. Similar challenges in lab capacity were seen in the difference in improvement in HCV screening. At the provincial clinic, HCV screening improved rapidly but only reached $40 \%$ at the district level. ART start time also remains a challenging indicator to improve in this province due to broader factors including patient distance from the clinics. As QI has become increasingly integrated into the clinic activities and led by clinic staff, the PCT and PAC can shift their focus to those quality issues that require a provincial-level approach.

There were a number of limitations to this work common to many studies of change associated with QI. It is largely based on programmatic data and documentation in the record. While the use of medical records data is a widely accepted approach to quality measurement, some portion of the reported improvements may have been due to changes in documentation rather than improvement in practice [28]. Second, this model has shown sustainability of the PCT and in documented improvement at one year 


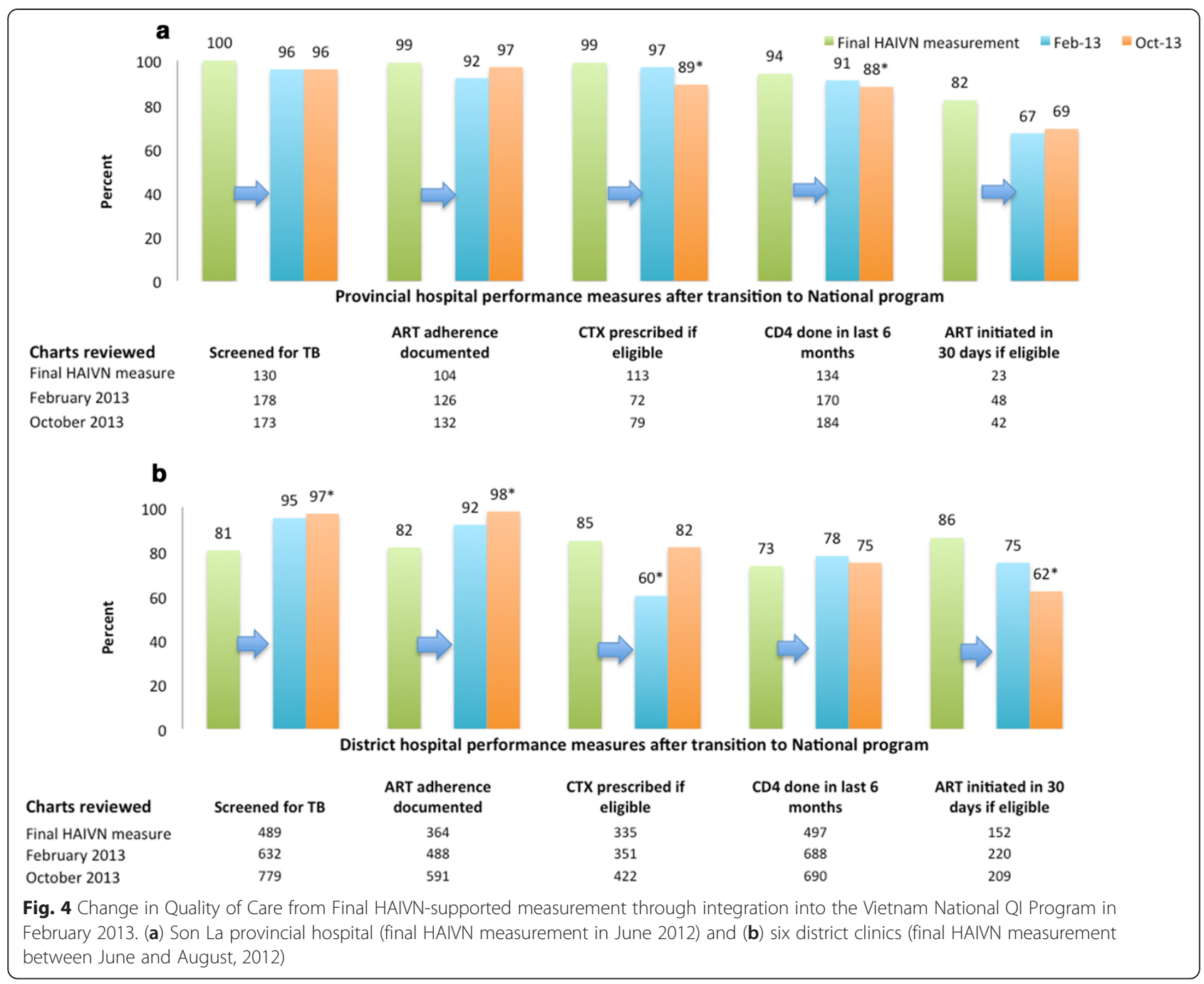

after integration into a national program. However, longer term benefit and ongoing leadership and support by the provincial team needs to be demonstrated. Finally, as with any pre-post study, we could not rule out other factors resulting in improved clinic quality. However, no large external factors at the provincial or district levels that could have resulted in cross-indicator improvement were identified.

\section{Conclusions}

In conclusion, we found that integrating coaching to improve systems into more traditional clinical skills-focused training was effective at increasing efforts to address gaps and improve the quality of clinical care. The model of building a team based on existing public sector staff and responsibilities was associated with strengthened leadership and rapid spread of QI, the capacity to recognize and address provincial-level system gaps, and the ability to ensure a seamless transition to an expanding national QI program. Further studies should examine whether the model and associated QI work can be sustained over time and adapted for effective replication in other setting and disease areas. Effective spread of the PCT model could be of tremendous value to other resourcelimited countries working towards strengthening systems to support universal access to quality healthcare.

\section{Abbreviations}

ALT: Alanine aminotransferase; ART: Antiretroviral therapy;

CTX: Cotrimoxazole; HAIVN: Partnership for Health Advancement in Vietnam; HCV: Hepatitis C virus; HCW: Health care worker; Hgb: Hemoglobin;

PAC: Peoples' AIDS Committee; TB: Tuberculosis; Ql: Quality improvement; VAAC: Vietnam Administration for AIDS Control.

\section{Competing interests}

The authors declare that they have no competing interests.

\section{Authors' contributions}

LC and LRH drafted the initial manuscript. HVD and HTH implemented the study in the province. PTD and HLN created the database. All authors contributed to study design and reviewed and edited the final manuscript. All authors read and approved the final manuscript. 


\section{Acknowledgements}

We thank the health care workers in Son La province for their enthusiastic participation in the work. The work was supported by a cooperative agreement through the United States Centers for Disease Control and Prevention, U2GPS001177-04

\section{Author details}

${ }^{1}$ Brigham and Women's Hospital, 75 Francis St, Boston, MA 02115, USA. ${ }^{2}$ The Partnership for Health Advancement in Vietnam, Beth Israel Deaconess Medical Center, 1309 Beacon St, Brookline, MA, USA. ${ }^{3}$ Son La Department of Health, Son La Province, Vietnam. ${ }^{4}$ The Partnership for Health Advancement in Vietnam, Beth Israel Deaconess Medical Center, 57 Ly Nam De St, Hanoi, Vietnam. ${ }^{5}$ Ariadne Labs, a joint Partnership with Brigham and Women's Hospital and Harvard School of Public Health, Landmark Center, Boston, MA, USA. ${ }^{6}$ Harvard Medical School, Boston, MA, USA.

Received: 31 December 2014 Accepted: 29 June 2015 Published online: 17 July 2015

\section{References}

1. Global update on HIV treatment 2013: results, impact and opportunities: WHO report in partnership with UNICEF and UNAIDS. [http://www.unaids.org/en/resources/documents/2013/ 20130630_treatment_report]. Accessed 4 July 2015.

2. Wester CW, Bussmann H, Avalos A, Ndwapi N, Gaolathe T, Cardiello P, et al. Establishment of a public antiretroviral treatment clinic for adults in urban Botswana: lessons learned. Clin Infect Dis. 2005;40(7):1041-4.

3. Bussmann C, Rotz P, Ndwapi N, Baxter D, Bussmann H, Wester CW, et al. Strengthening healthcare capacity through a responsive, country-specific, training standard: the KITSO AIDS training program's support of Botswana's national antiretroviral therapy rollout. Open AIDS J. 2008;2:10-6.

4. Barker PM, McCannon CJ, Mehta N, Green C, Youngleson MS, Yarrow J, et al. Strategies for the scale-up of antiretroviral therapy in South Africa through health system optimization. J Infect Dis. 2007;196 Suppl 3:S457-463.

5. Toro PL, Rabkin M, Flam R, El-Sadr W, Donahue M, Chadwick E, et al. Training multidisciplinary teams to deliver high-quality HIV care to families in resource-limited settings: the MTCT-Plus initiative experience. J Assoc Nurses AIDS Care. 2012;23(6):548-54.

6. Morris MB, Chapula BT, Chi BH, Mwango A, Chi HF, Mwanza J, et al. Use of task-shifting to rapidly scale-up HIV treatment services: experiences from Lusaka, Zambia. BMC Health Serv Res. 2009;9:5.

7. Schneider A. How quality improvement in health care can help to achieve the Millennium Development Goals. Bull of the World Health Organ. 2006;84(4):259

8. World Health Organization. The World Health Report 2013. Geneva, Switzerland: WHO; 2013.

9. Rowe AK, Onikpo F, Lama M, Deming MS. The rise and fall of supervision in a project designed to strengthen supervision of Integrated Management of Childhood IIlness in Benin. Health Pol Plann. 2010;25(2):125-34.

10. Carlo WA, Goudar SS, Jehan I, Chomba E, Tshefu A, Garces A, et al. Newborn-care training and perinatal mortality in developing countries. New Engl J Med. 2010;362(7):614-23.

11. O'Brien MA, Rogers S, Jamtvedt G, Oxman AD, Odgaard-Jensen J, Kristoffersen DT, et al. Educational outreach visits: effects on professional practice and health care outcomes. Cochrane Database Syst Rev. 2007:4:CD000409.

12. Zwarenstein M, Fairall LR, Lombard C, Mayers P, Bheekie A, English RG, et al. Outreach education for integration of HIV/AIDS care, antiretroviral treatment, and tuberculosis care in primary care clinics in South Africa: PALSA PLUS pragmatic cluster randomised trial. BMJ. 2011;342:d2022.

13. Schull MJ, Banda H, Kathyola D, Fairall L, Martiniuk A, Burciul B, et al. Strengthening health human resources and improving clinical outcomes through an integrated guideline and educational outreach in resource-poor settings: a cluster-randomized trial. Trials. 2010;11:118.

14. Zaeh S, Kempker R, Stenehjem E, Blumberg HM, Temesgen O, Ofotokun I, et al. Improving tuberculosis screening and isoniazid preventive therapy in an HIV clinic in Addis Ababa, Ethiopia. Int J Tuberc Lung Dis. 2013;17(11):1396-401.

15. Massoud MR, Mensah-Abrampah N, Sax S, Leatherman S, Agins B, Barker P, et al. Charting the way forward to better quality health care: how do we get there and what are the next steps? Recommendations from the Salzburg Global Seminar on making health care better in low- and middleincome economies. Int J Qual Health Care. 2012;24(6):558-63.
16. Heiby J. The use of modern quality improvement approaches to strengthen African health systems: a 5-year agenda. Int J Qual Health Care. 2014;26(2):117-23.

17. Agyeman-Duah JN, Theurer A, Munthali C, Alide N, Neuhann F. Understanding the barriers to setting up a healthcare quality improvement process in resource-limited settings: a situational analysis at the Medical Department of Kamuzu Central Hospital in Lilongwe, Malawi. BMC Health Serv Res. 2014;14:1

18. Sharma A, Chiliade P, Michael Reyes E, Thomas KK, Collens SR, Rafael Morales J. Building sustainable organizational capacity to deliver HIV programs in resource-constrained settings: stakeholder perspectives. Glob Health Action. 2013;6:22571.

19. Schwarz D, Schwarz R, Gauchan B, Andrews J, Sharma R, Karelas G, et al. Implementing a systems-oriented morbidity and mortality conference in remote rural Nepal for quality improvement. BMJ Qual Saf. 2011;20(12):1082-8.

20. Thanprasertsuk S, Supawitkul S, Lolekha R, Ningsanond P, Agins BD, McConnell MS, et al. HIVQUAL-T: monitoring and improving HIV clinical care in Thailand, 2002-08. Int J Qual Health Care. 2012;24(4):338-47.

21. Franco LM, Marquez L. Effectiveness of collaborative improvement: evidence from 27 applications in 12 less-developed and middle-income countries. BMJ Qual Saf. 2011;20(8):658-65.

22. UNAIDS. UNAIDS Report on the Global AIDS Epidemic 2013. [http://www.unaids.org/en/resources/documents/2013/ 20130923_UNAIDS_Global_Report_2013].

23. An annual update on the HIV epidemic in Vietnam. [http://www.nihe.org.vn/uploads/An\%20annual\%20update\%20on\% 20the\%20HIV\%20epidemic\%20in\%20Viet\%20Nam.pdf] 10/2014. Accessed 4 July 2015.

24. Vietnam General Statistics Office. Household Living Standard Survey. [http://www.gso.gov.vn]; 2012. Accessed 4 July 2015.

25. WHO. Standards for quality HIV care: a tool for quality assessment, improvement, and accreditation. [http://www.who.int/hiv/pub/prev_care/ en/standardsquality.pdf]. Accessed 4 July 2015

26. National Quality Center. Guidelines based indicators for HIV care. [http://nationalqualitycenter.org/index.cfm/6115/19392]. Accessed 4 July 2015.

27. Ivers NM, Grimshaw JM, Jamtvedt G, Flottorp S, O'Brien MA, French SD, et al. Growing Literature, Stagnant Science? Systematic Review, Meta-Regression and Cumulative Analysis of Audit and Feedback Interventions in Health Care. J Gen Intern Med. 2014;29(11):1534-41.

28. Donabedien A. Evaluating quality of medical care. Millbank Q. 1996;84(4):691-279.

\section{Submit your next manuscript to BioMed Central and take full advantage of:}

- Convenient online submission

- Thorough peer review

- No space constraints or color figure charges

- Immediate publication on acceptance

- Inclusion in PubMed, CAS, Scopus and Google Scholar

- Research which is freely available for redistribution 